\title{
FACTORS THAT INFLUENCE THE SUCCESS OF HSR STATIONS
}

\author{
Frank Hanna ${ }^{1}$, Jeremy Kaufmann ${ }^{2}$ \\ ${ }^{I}$ Associate Professor, Civil Engineering Technology, Environmental Management \& Safety, Rochester Institute of \\ Technology, Rochester, New York 14623-5603, United States \\ ${ }^{2}$ Civil Engineering Technology Student, Rochester Institute of Technology, Rochester, New York 14623-5603, United \\ States
}

\begin{abstract}
High-Speed Rail (HSR) is an intermodal transport option on a passenger's journey with nodal point-to-point connections to stations. This makes the station an important factor in determining the success of HSR. With networks that are proposed, being constructed, and currently operating in Europe, Asia, and North America it is important that the stations are built to the highest quality standards. This paper is a comparative study of the proposed high-speed train stations in the United States and those already operating overseas. This will help to ensure that the proposed stations are going to meet the needs of passengers and therefore be successful. Factors of analysis include the location, size, accessibility, and serviceability of the stations. It is determined that the stations analyzed in Europe and Asia are having great success, located in the midst of densely populated cities, built of adequate size to handle passenger flows, accessible by the majority, and providing services that meet the needs of the customers. However, along the proposed network in the United States, these factors should be considered prior to construction as they may not currently be planning them all to be of the same quality.
\end{abstract}

Keywords - HSR stations; station location; station size; accessibility; intermodality; serviceability ****

\section{INTRODUCTION}

High-Speed Rail (HSR) is the way of the future for passenger transport. "The one technology on the horizon that fits the geographic scale of megaregions and can help spur more intensive development of those regions is highspeed rail" (Florida, 2010). A station located in the center of each city within the megaregion will connect via HSR forming a more economically efficient region. This paper is a comparative study of the proposed high-speed train stations in the United States and those already operating overseas. The network and its role in the transportation of passengers will be mentioned throughout this paper. This is because there is a direct correlation between networks and the stations located along them. A successful network can be justification for expansion. As a network grows and reaches new cities, it may be necessary to modernize, or renovate, a pre-existing station, or construct a new one built and operating at the highest quality.

While much focus has been placed on the operating speeds of trains or other aspects of HSR, this paper focuses on the station. A station is not the starting point or final destination on a passenger's journey. Therefore the station serves as a transition point for the passengers, and plays the most important role in the success of HSR. An ideal network could be planned, but if there is failure in and around the stations, the network has failed. The following are important factors in determining the success of HSR stations: the station location, station size, accessibility, and serviceability.

\section{THE STATION LOCATION}

The cities in which the station is located, the location within each city, and the distance between stations is crucial for city development. The HSR station has an important job, as Richard Florida states in his book The Great Reset, "We need to ensure that key cities and regions continue to circulate people, goods, and ideas quickly and efficiently" (Florida, 2010). By being located in the most densely populated cities, the train station can circulate large numbers of people in the shortest amount of time.

Two densely populated cities separated by a long distance can be connected by a point-to-point or "city center-to-city center" direct train connection. This type of high-speed service has had success on the Paris-Lyon, Paris-London, and Tokyo-Osaka direct lines (Blum, Haynes, \& Karlsson, 1997). However, point-to-point connections over long distances are not always possible based on a countries urban development. Where many cities are located within a given region, a HSR network can link them together creating a new megaregion. A megaregion is a corridor of several large cities located 160-800 kilometers $(\mathrm{km})$ apart. This type of service has seen success in Germany where many cities are connected together and each link is at a medium distance, creating a large functional region (Blum et al., 1997).

All the cities along a network are not of the same size. Different scale cities need different site locations (Hong, Dong, \& Song, 2012). There are three types of stations to consider when deciding where to locate it within the city. The Urban-centered, Urban-edged, and Urban-fringed station (Hong et al., 2012). 


\subsection{Urban-Centered}

The Urban-centered station is located $1-5 \mathrm{~km}$ from the center of the city. The large passenger flow that is connected to Mega-cities makes this the most accessible station (Hong et al., 2012). This type of station is the most successful as it is highly accessible and places its passengers in the midst of businesses, shopping centers, restaurants, and tourist attractions. Due to the highly developed nature of large cities, however, there are few places that this type of station is feasible unless there is already a centrally located station that just needs to be modernized. An example of this is St. Pancras International, located in London, which has had great success since being restructured to meet the needs of HSR (Garmendia, Ribalaygua, \& Ureña, 2012).

\subsection{Urban-Edged}

The Urban-edged station is located $5-15 \mathrm{~km}$ from the center of the city. This type of station lacks accessibility compared to the urban-centered station due to its relative distance from the highest populated area (Hong et al., 2012). This is the most commonly built station as most large cities are too developed to place the station in the center of it. Although it is less accessible than the Urban-centered station, it is still fairly accessible via public transportation systems offered within the city. An example of a successful Urban-edged station is Lyon-Part Dieu, Located in France, which creates new business opportunities further from the center of the city (Garmendia et al., 2012).

\subsection{Urban-Fringed}

The Urban-fringed station is located beyond $15 \mathrm{~km}$ from the center of the city. This station has low accessibility due to lack of highway connection. It is mostly built in medium and small cities (Hong et al., 2012). Although this station has low accessibility, there are benefits to the surrounding region. "A good way to get rich is to be near other rich places; remoteness is costly," Ryan Avent as cited in (Florida, 2010). An example of this can be seen in China. The introduction of these types of stations to a city allows for development such that, in the future, the station will become centrally located. This occurs through the attraction of businesses to the area creating a new economic region (Zhu, Wang, \& Xue, 2009).

In conclusion, the city itself plays a role in the determination of a station's site location. In a large, highly developed city, renovating an existing station to meet the needs of HSR is a good option. However, if there is no room for expansion, then a new station on the edge of the city should be built. If the city is only of medium size, then a high speed train station would be too large for the city center and must be built further away from the city. In any case, the location of the station within the city should be determined by the size of the city and its current and expected future development.

\section{THE STATION SIZE}

HSR stations need to be large enough to provide many ticket vendors, allowing for multiple lines, so that passengers do not have to arrive hours before their departure time in order to catch the train. Another advantage to a larger station is that more tracks can be provided, increasing the number of arrivals and departures at any given time, thus increasing the passenger flow through that station. The more passengers in the station, the larger the waiting area needed. Near the waiting area there should be restaurants and shops so that passengers have options as to how to utilize their time spent at the station. Each of these sections adds up making for a larger station. The factors that should influence the size of each station are the number of passengers passing through that station per year, and the current and anticipated future population of the city.

\subsection{Size of Train Station vs. Number of Passengers per Year}

The size of nine train stations along HSR networks in seven countries versus the number of passengers that pass through that station per year are shown in Figure 1. The data was extracted from several sources for the purpose of this article, and is current except for the Transbay Center and Union Station which use estimated values upon completion as they are located in the United States and are currently under construction. 


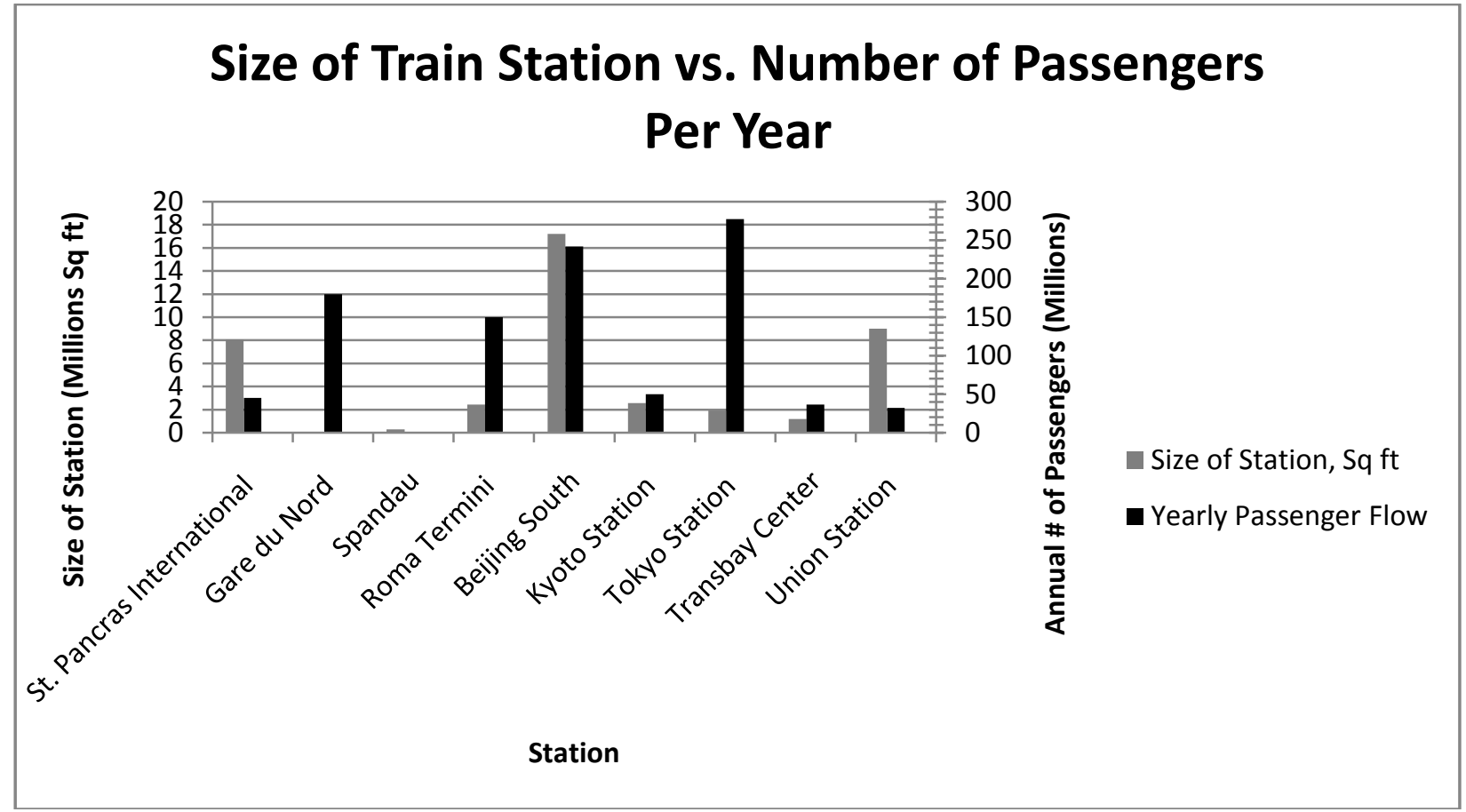

*Note: The size of Gare du Nord and the number of passengers for Berlin Spandau are unavailable to the authors.

Fig 1: The size of nine train stations vs. the yearly passenger flow through each station. Adapted from ("Beijing South Railway Station,") ("Berlin-Spandau Railway Station, Germany,") (Nakata, 2012) ("Union Station Master Plan," 2012) ("Building the "Grand Central Station of the West"," 2013) ("The world's busiest Train Stations," 2012) ("St. Pancras International Station, United Kingdom," 2012) ("Roma Termini," 2008) ("Japan Train Stations: Kyoto Station," 2000).

The first station to be analyzed will be St. Pancras International. This station was modernized and reopened in 2007 featuring shops and restaurants, becoming one of the largest landmarks in London with just over 8 million square feet (sq ft) serving as the gateway to Europe ("St. Pancras International Station, United Kingdom," 2012). St. Pancras International provides services to Europe via the Channel Tunnel. The reason this station was built this large was because Britain's HSR network is young compared to the rest of Europe's. They opened the Channel Tunnel in 2003, the first phase of their HSR plan (UIC, 2013). It is expected that once the network grows, the number of passengers traveling to different locations will increase, and thus the station was built to handle this future passenger flow.

The next station that shall be analyzed is Beijing South. This station was built from scratch and opened only a year after the St. Pancras remodeling was done. The 17 million sq $\mathrm{ft}$ station was built in about three years, has 24 platforms, a waiting area that can hold 10 thousand passengers, and serves 242 million passengers per year (p/y) ("Beijing South Railway Station,"). Urbanization in China is still under development, and the leaders of the country are using HSR as an important factor in their development plans (Zhu et al., 2009). This is why Beijing South was constructed so large. The goal is for the station to not only handle the passenger flow of today, but the passenger flow many years into the future.

Tokyo Station was originally opened in 1914, and restructured with now just under 2 million sq $\mathrm{ft}$ to handle the birth of HSR (Nakata, 2012). The Shinkansen bullet train was the world's first HSR service which began operation in Japan on October, 1st 1964 connecting Tokyo to Kyoto (Cohen \& Kamga, 2013). HSR has been well received by the Japanese population, and thus passenger flow volumes have increased heavily since HSR services began. Today, with over 277 million $\mathrm{p} / \mathrm{y}$, the station is overcrowded and new renovations may be in order.

The last station to be analyzed will be Union Station in Washington D.C. This station has served the D.C. Region for over 100 years, but is operating over capacity ("Union Station Master Plan," 2012). This is why, along with the proposal for HSR in the United States, the station is being renovated and modernized. It is expected that upon completion there will be 32 million $\mathrm{p} / \mathrm{y}$, but it is going to be 9 million sq $\mathrm{ft}$ so that it can handle the passenger flow for the next century ("Union Station Master Plan," 2012).

\subsection{Population of City vs. Number of Passengers per Year}

The population of the city in which the same nine stations reside versus the number of passengers that pass through each station per year is shown in Figure 2. Based on the data, collected from multiple sources, the same four stations will be analyzed more closely.

St. Pancras International located in London has a yearly passenger flow of 45 million p/y ("St. Pancras International 
Station, United Kingdom," 2012) while the city of London has a population of over 8 million people (UK National Statistics (web), 2013). The reason for the relatively low passenger flow is as stated in section 3.1, HSR in Britain is relatively young compared to the rest of Europe. They expect a higher future passenger flow, however, once their network becomes more developed.

Beijing South located in China has a passenger flow of 242 million p/y ("Beijing South Railway Station,") and a population of over 20 million people ("Beijing Population 2013," 2013). With the rapid increase in China's population, urbanization, and the increase in HSR popularity, their passenger flow is expected to increase.
Tokyo Station has a passenger flow of 277 million p/y (Nakata, 2012) and Tokyo has a population of of over 13 million people ("Tokyo Population 2013," 2013). HSR is the prefered mode of transportation by the majority of the Japanese population, which is why their passenger flow is so large.

Union Station in Washington D.C. has an expected passenger flow of 32 million p/y ("Union Station Master Plan," 2012) upon completion, and the population is around 600 thousand people(US Census Bureau (web), 2013). This expected flow is because Washington D.C. is one of the largest tourist attraction cities in the United States as it is the capital city.

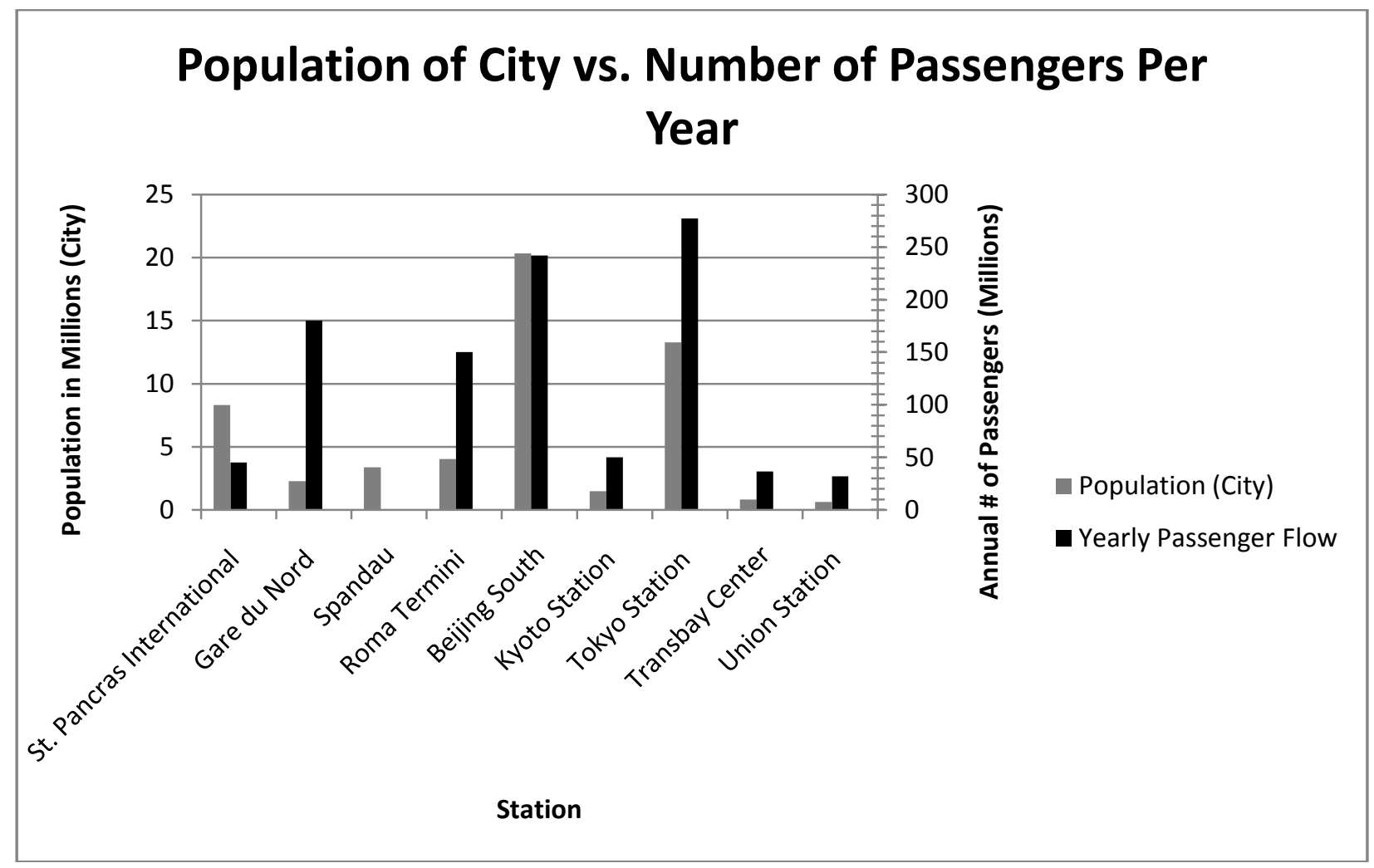

*Note: Populations are for the year 2012.

Fig 2: The population of nine cities vs. the yearly passenger flow through each station. Adapted from ("Beijing Population 2013,"

2013) (US Census Bureau (web), 2013) ("Kyōto (Japan)," 2013) ("Union Station Master Plan," 2012) ("Building the "Grand

Central Station of the West"," 2013) (Nakata, 2012) ("Tokyo Population 2013," 2013) ("The world's busiest Train Stations," 2012)

("St. Pancras International Station, United Kingdom," 2012) ("Roma (Province)," 2013) ("Roma Termini," 2008) (Institut

National de la Statistique et des Etudes Economiques, 2013) ("Japan Train Stations: Kyoto Station," 2000) ("Germany: Berlin," 2013) ("Beijing South Railway Station,") ("California (USA)," 2013) (UK National Statistics (web), 2013).

After analyzing both Figures 1 and 2, a conclusion about the success of each station to move passengers can be drawn. While St. Pancras International's passenger flow is relatively low for a European Station, the network in Britain is relatively young, and thus the future passenger flow volume is expected to be higher. This is why the station was built at over 8 million sq ft.

The same applies to Beijing South as urbanization is a new concept in China, and the station was only recently constructed in 2008. China is experiencing rapid population growth, and thus an answer was needed in the area of transportation for such a large population. The leaders of the country decided HSR was the route they wanted to take, and the passenger flow is expected to be even higher in the future.

Tokyo Station has the largest passenger flow of the nine stations analyzed. This is because Tokyo Station was one of the first HSR stations, and the Shinkansen lines in Japan have high popularity. The small station, built a long time ago is now operating above capacity. 
Union Station in Washington D.C. is another case of an old station being modernized in order to handle the expected passenger flows that come with HSR. Currently operating over capacity, as a non-HSR station, it is under renovation and will be 9 million sq $\mathrm{ft}$ upon completion. The expected passenger flow upon completion may not be large enough to grant such a large station, but it not being reconstructed to handle just the passengers of today, but the passenger flow for the next century.

In conclusion, each city needs to determine the size of the station to be built along their HSR network based upon these factors. The station size should be determined by the number of people located within each city, and its suburbs, the number of people attracted to that region, the current and future development plans, and the current and expected future growth of that city.

\section{ACCESSIBILITY}

Accessibility is, "The ease with which an individual has an opportunity to reach or access a specific place, infrastructure, amenity, job opportunity or to participate in an activity in general" (Tapiador, Burckhart, \& MartíHenneberg, 2009). For a station to be successful it has to be easily accessed by the people it was built to serve. With greater access comes greater rail use (Brons, Givoni, \& Rietveld, 2009), and the highly accessible station will produce satisfied passengers. When building a network for the first time this should be taken into consideration so that the station is already easily accessible to the majority of the population. Easier access to everyone else can be introduced over time. The introduction of a highly-accessible station that connects train riders to the rest of the transportation network within the city is necessary (Lane, 2012). This makes the HSR station an important part of any intermodal transport system.

\subsection{Intermodality}

Intermodality is, "A characteristic of a transport system that allows at least two different modes to be used in an integrated manner in a door-to-door transport chain" (European Commission, 2001a). Door-to-door travel time, convenience, and reliability of the entire chain of a passenger's journey is more important than station-to-station (Givoni \& Banister, 2012). The scheduling system within the station should be one such that when trains arrive there are other modes of transportation waiting to take passengers to their final destination. If a passenger arrives after a three hour journey and has to wait an additional hour to go from the station to their final destination, they may consider a mode other than HSR to take them where they need to go. This makes the station the point of transition for passengers whose intermodal journey involves HSR. The station should also offer Park and Ride services. Park and Ride and similar terms have been used to express the combination of modes of transportation (Tapiador et al., 2009). These are things such as parking garages and bicycle racks that allow you to park your car or chain your bike at the station and then ride the train to your destination. A successful high-speed train station provides many different transportation choices, to and from the station.

Two things should be considered when deciding what modes of transportation to provide at each station. The first is that the station with the most modes is the most easily accessible. Such examples include car, bus, subway, airplane, bicycle etc. However, it is not just the amount of options that is important. The second consideration should be the types of modes available. The transport choices should fit the needs of the citizens of that region. An example of this is Dutch rail, in which the majority of citizens ride bikes to get to destinations within the city. In 2011, the Houten Transferium opened a bicycle parking facility which holds more than 3,000 bicycles directly under the rail platforms, allowing citizens to transfer from one transport mode to another with ease (Bicycledutch, 2013).

\section{SERVICEABILITY}

The station's serviceability is a vital factor in its success, as the passenger's satisfaction is important. A satisfied customer is more likely to continue using the service and recommend the service to their friends (Anderson \& Fornell as cited in (Chou \& Kim, 2009). A satisfied customer is one who can enter the station, purchase a ticket, advance through security quickly and without harassment, and in a matter of minutes step onto the train that will be taking them to their destination. This is the service provided by a truly intermodal station operating at the highest level of service. However, there are instances when passengers spend time waiting in the station for one reason or another, whether it is a layover between trains, or waiting for the bus to arrive to take them into the city. Therefore, the station needs to provide services such as restaurants and shopping centers, and these services need to fit the needs of the passengers who access the station. It also needs to be a beautiful structure that invites people in, and the quality of service needs to be of the highest distinction. With a good image comes a higher perceived quality of service by the customer (Chou \& Kim, 2009).

When St. Pancras International was renovated, it was restored to the Victorian-era style and expanded to include retail and hospitality areas. Some of these services include parking and bike racks, boutiques, bars, and restaurants ("St. Pancras International Station, United Kingdom," 2012). Tokyo Station features a hotel so that travelers to the area can stay right at the station and have immediate access to the HSR network. The latest renovations have restored the station to its original glory (Nakata, 2012). Beijing South Station is not only a key station on their HSR network, but a major urban building. It is designed in such a way that it is convenient and highly efficient, with direct and seamless passenger flow ("Beijing South Station / TFP Farrells," 18 Sep 2012). These stations have successfully met the needs of the passengers utilizing them, and it is services like these that will make passengers continue to travel via HSR through those stations. 


\section{CONCLUSIONS}

In this paper, the stations along HSR networks that are proposed, being constructed, and in operation in Europe, Asia, and North America were compared. The cities these stations are located in, the location within each city, and the distance between stations was analyzed. It was determined that the stations should be located in the most densely populated cities located $160-800 \mathrm{~km}$ apart. It was also shown that there were three potential station locations within a city: the Urban-centered, Urban-edged, or Urbanfringed station. The Urban-centered station was shown to have the most advantages by being located in the heart of the city, and being the most easily accessible. This type of station is not always a feasible option though, and it was determined that the site location should be chosen based on the size of the city, and the current and future development plans.

After the location was determined, the size of the station was analyzed based on the population of the city and the number of passengers that pass through the station per year. St. Pancras International, Beijing South, Tokyo Station, and Union Station were looked at more closely. It was determined that the station should be built based on the number of people located within that region, the current and future development plans, and the current and expected future growth of that city.

Now that the station is large enough to handle the passenger flow, it needs to be accessible. The access of the station and its integration with the rest of the transport network is of great importance (Givoni \& Banister, 2012). This deals with the intermodality of the network as passengers are not only worried about station-to-station but door-to-door time, and ease along their journey. In order for a station to be truly intermodal it must offer many different transportation methods, and these should be based on the travel preferences of the citizens within each city.

Lastly, the appearance and serviceability of the station determine customer satisfaction. The building needs to look good so as to invite passengers in. Once inside they need to be comfortable, and have options as to how to spend their time within the station while waiting for a train to depart, or another mode of transportation to take them into the city. A satisfied customer is evidence that the station has successfully done its job.

In conclusion, as HSR networks expand throughout the world, stations are being constructed along them. The United States is currently planning their network in a desire to connect their cities together via centrally located stations with access to that network. However, the factors discussed should be considered prior to the construction of these stations if they are to be successful.

\section{REFERENCES}

[1] Beijing Population 2013. (2013). Retrieved December 13, 2013, from http://www.worldpopulationstatistics.com/beijingpopulation-2013/

[2] Beijing South Railway Station. Retrieved 7 Sep, 2013, from http://www.ebeijing.gov.cn/feature_2/YunkunBeijing Living/Articles/t1094100.htm

[3] Beijing South Station / TFP Farrells. (18 Sep 2012). Retrieved 7 Sep, 2013, from http://www.archdaily.com/272425

[4] Berlin-Spandau Railway Station, Germany. Retrieved 20 Sep, 2013, from http://www.gmparchitekten.com/uploads/tx_gmpprojects/0649_e_Ba hnhof_Spandau_webN.pdf

[5] Bicycledutch. (2013). Modern indoor bicycle parking facilities.

[6] Blum, U., Haynes, K. E., \& Karlsson, C. (1997). Introduction to the special issue The regional and urban effects of high-speed trains. The Annals of Regional Science, 31(1), 1-20. doi: 10.1007/s001680050036

[7] Brons, M., Givoni, M., \& Rietveld, P. (2009). Access to railway stations and its potential in increasing rail use. Transportation Research Part A: Policy and Practice, 43(2), 136-149. doi: http://dx.doi.org/10.1016/j.tra.2008.08.002

[8] Building the "Grand Central Station of the West". (2013). Retrieved 1 Sep, 2013, from http://transbaycenter.org/uploads/2009/11/TTC-factsheet-March-2013.pdf

[9] California (USA). (2013). Retrieved December 13, 2013, from http://www.citypopulation.de/USACalifornia.html

[10] Chou, J.-S., \& Kim, C. (2009). A structural equation analysis of the QSL relationship with passenger riding experience on high speed rail: An empirical study of Taiwan and Korea. Expert Systems with Applications, 36(3, Part 2), 6945-6955. doi: http://dx.doi.org/10.1016/j.eswa.2008.08.056

[11] Cohen, J., \& Kamga, C. (2013). Financing high speed rail in the United States and France: The evolution of public-private partnerships. Research in Transportation Business \& Management, 6(0), 6270. doi: http://dx.doi.org/10.1016/j.rtbm.2012.11.013

[12] European Commission. (2001a). Thematic synthesis of transport research results. Freight intermodality, Paper 10, Transport RTD Programme.

[13] Florida, R. (2010). The Great Reset: how new ways of living and working drive post-crash prosperity (1st ed.). 10 East 53rd Street, New York, NY 10022: HarperCollins Publishers.

[14] Garmendia, M., Ribalaygua, C., \& Ureña, J. M. (2012). High speed rail: implication for cities. Cities, 29, Supplement 2(0), S26-S31. doi: http://dx.doi.org/10.1016/j.cities.2012.06.005

[15] Germany: Berlin. (2013). Retrieved December 10, 2013 , 
http://www.citypopulation.de/php/germany-

berlin.php

[16] Givoni, M., \& Banister, D. (2012). Speed: the less important element of the High-Speed Train. Journal of Transport Geography, 22(0), 306-307. doi: http://dx.doi.org/10.1016/j.jtrangeo.2012.01.024

[17] Hong, L. Y., Dong, X. C., \& Song, K. L. (2012). Analysis on the Site Location and Impact Factors of the High-speed Rail Station-As a Case of the BeijingShanghai High-speed Rail Stations. Applied Mechanics and Materials, 178-181, 1631-1634. doi: 10.4028/www.scientific.net/AMM.178-181.1631

[18] Institut National de la Statistique et des Etudes Economiques, F. w. (2013). Paris (France): Department \& City - Statistics \& Maps by »City Population $\ll$. Retrieved 15 Sep., 2013, from http://www.citypopulation.de/php/france-paris.php

[19] Japan Train Stations: Kyoto Station. (2000). Retrieved 24 Sep, 2013, from http://www.japanvisitor.com/japan-city-guides/japanstations/kyoto-statio

[20] Kyōto (Japan). (2013). Retrieved December 13, 2013, from http://www.citypopulation.de/JapanKyoto.html

[21] Lane, B. W. (2012). On the utility and challenges of high-speed rail in the United States. Journal of Transport Geography, 22(0), 282-284. doi: http://dx.doi.org/10.1016/j.jtrangeo.2012.01.030

[22] Nakata, H. (2012). Tokyo Station's Marunouchi side restored to 1914 glory, The Japan Times. Retrieved from

http://www.japantimes.co.jp/news/2012/10/23/refere nce/tokyo-stations-marunouchi-side-restored-to1914-glory/

[23] Roma (Province). (2013). Retrieved December 10, 2013, from http://www.citypopulation.de/php/italylazio.php?adm2id=058

[24] Roma Termini. (2008). Italy's major stations. Retrieved 5 Sep, 2013, from http://www.grandistazioni.it/cms/v/index.jsp?vgnexto id=ae2172ceeae7b110VgnVCM1000003f16f90aRC RD

[25] St. Pancras International Station, United Kingdom. (2012). Retrieved 15 Sep, 2013, from http://www.railway-

technology.com/projects/stpancrasinternation/

[26] Tapiador, F. J., Burckhart, K., \& Martí-Henneberg, J. (2009). Characterizing European high speed train stations using intermodal time and entropy metrics. Transportation Research Part A: Policy and Practice, 43(2), 197-208. doi: http://dx.doi.org/10.1016/j.tra.2008.10.001

[27] The world's busiest Train Stations. (2012). Retrieved 15 Sep, 2013, from http://www.railwaytechnology.com/features/featureworlds-busiest-trainstations

[28] Tokyo Population 2013. (2013). Retrieved December 13, 2013, from http://worldpopulationreview.com/worldcities/tokyo-population/
[29] UIC. (2013). High Speed lines in the world. Retrieved 29 Sep, 2013, from http://uic.org/IMG/pdf/20130701_high_speed_lines_i n_the_world.pdf

[30] UK National Statistics (web). (2013). Greater London (United Kingdom): Boroughs - Statistics \& Maps by »City Population«. Retrieved 17 Nov., 2013, from http://www.citypopulation.de/php/ukgreaterlondon.php

[31] Union Station Master Plan. (2012). Retrieved 12 Sep, 2013, from http://www.amtrak.com/ccurl/919/171/WashingtonUnion-Station-Master-Plan-201207.pdf

[32] US Census Bureau (web). (2013). District of Columbia / DC (USA): Counties \& Incorporated Places - Statistics \& Maps by »City Population «. Retrieved $15 \quad$ Sep., 2013, from http://www.citypopulation.de/php/usadistrictofcolumbia.php

[33] Zhu, Y., Wang, H., \& Xue, B. (2009). Land usage and development in high-speed train stations and its traffic impact analysis. 345, 1152-1157. doi: $10.1061 / 41039(345) 191$ 